\title{
Eustáquio Ornelas Cota, A formação da Coleção Latino-Americana do MoMA: arte, cultura e política (1931-1943), Judiaí, Paco Editorial, 2019, pp.236.
}

Copyright: () 2020. Cavadía, A. Este es un artículo de acceso abierto, distribuido bajo los términos de la licencia https://creativecommons.org/licenses/by-nc$\mathrm{sa} / 4.0 /$ la cual permite el uso sin restricciones, distribución y reproducción en cualquier medio, siempre y cuando que el original, el autor y la fuente sean acreditados.

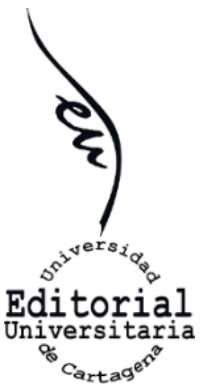

El historiador Eustáquio Ornelas Cota escribe A formação da Coleção LatinoAmericana do MoMA: arte, cultura e política (1931-1943) en el marco del trabajo de investigación desarrollado en su carrera de doctorado (2017) y Máster (2016) en Historia Social de la Universidad de São Paulo (FFLCH / USP). ${ }^{1}$ Cota estudia el proceso de formación de la colección latinoamericana del Museo de Arte Moderno de Nueva York (MoMA) teniendo en cuenta la acción diplomática de los Estados Unidos sobre los países vecinos y la construcción de relaciones de dominación entre 1931-1943. Para ello analiza las conexiones internacionales y la influencia de administradores culturales en la constitución de la colección de arte moderno latinoamericano del MoMA y su musealización como satélite del arte moderno.

Este libro hace parte de las investigaciones interesadas en el área cultural latinoamericana a principio del siglo XX que abordan la aparición de occidente como sujeto hegemónico ${ }^{2}$, la transformación del panorama cultural $^{3}$ y los intercambios receptivos del circuito internacional del arte ${ }^{4}$. Cota problematiza el lugar del arte latinoamericano en la trama política y diplomática de Estados Unidos. Este cuestiona las motivaciones que llevaron a la dirección del MoMA a estimular la circulación de obras de artistas latinoamericanos en plena Segunda Guerra Mundial. Plantea como hipótesis que, el acervo inicial del MoMA desde 1933 comenzó a tomar una nueva dimensión como puente entre EE.UU. y otros países vecinos, a cargo de Alfred Barr Jr. y Lincoln Kirstein, ligados a las políticas del gobierno de Franklin Delano Roosevelt. En esta línea, Cota aborda la circulación de capitales financieros para promoción cultural, el impacto heterogéneo de la modernización en el continente americano, los interese detrás del incremento de las actividades culturales y la especialización de las practicas museológicas.

\footnotetext{
${ }^{1}$ Entre los antecedentes de este libro del historiador Brasilero se encuentra el articulo 'Um 'empreendimento pioneiro': o catálogo da Coleção Latino-Americana do MoMA (1931-1943)", Faces da História, v. 2, n. 1, 2017, pp. 63-79; la tesis A Formação da Coleção Latino-Americana do Museu de Arte Moderna de Nova York: Cultura e Política (1931-1943). Tesis de Maestría en Historia Social, Universidad de São Paulo, São Paulo, 2016; y la ponencia "Cultura e política na formação da Coleção de Arte Latino-americana do MoMA (1935-1943)”. XXVIII Simpósio Nacional de Historiadores, Florianopolis, 2015

2 Joaquín Barriendos, La idea del arte latinoamericano. Estudios globales del arte, geografías subalternas, regionalismos críticos. Tesis de doctorado en Historia del arte, Universidad de Barcelona, Barcelona, 2013; Mariana Cerviño, "Modernidades periféricas en el circuito internacional de arte internacional, en la década del noventa". Revista Travessias. n. 5, v.3, 2011, pp. 1-22; Elsa Flores, Latinoamérica: construcción de modelos de la «Tradición de lo nacional» a la tradición de lo latinoamericano. En Marina Ravera (Comp.), Estética y critica. Los signos del arte, Buenos Aires, Ed. Universitaria de Buenos Aires, 1998.

${ }^{3}$ Damián Bayón, América Latina y sus artes, México, Siglo XXI, 2000; Matías Marambio, Campo intelectual y artes visuales: Marta Traba y la formación de una crítica artística Latinoamericana. Tesis de Maestría en Estudios Latinoamericanos, Universidad de Chile, Santiago de Chile, 2013; Michael Gordon, Pan-American Dreams: Art, Politics, and Museum-Making at the OAS, 1948-1976. Tesis de doctorado en Filosofía, Universidad de Texas, Austin, 2012.

${ }^{4}$ Luisa Arias, "Nuevos planteamientos museográficos en los museos de arte contemporáneo: de las primeras críticas al museo en los albores del siglo XX a los actuales 'microrrelatos"', Complutum, v. 26, n.2, 2015, pp.133-143; M. A Leigh, Building the Image of Modern Art. The Rhetoric of Two Museums and the Representation and Canonization of Modern Art (1935-1975): The Stedelijk Museum in Amsterdam and the Museum of Modern Art in New York. Tesis de Doctorado, Universidad de Leiden, Países Bajos, 2008.
} 
En el primer capítulo, el historiador estudia a través del prefacio del catalogo de la colección latinoamericana del MoMA las referencias al arte latinoamericano entre 1931 y 1943. En este Cota identifica que la mudanza del arte nuevo proveniente de Francia, España, Rusia, Holanda y Alemanía se relaciona con la intención del MoMA de posicionarse como nuevo polo artístico-cultural de la modernidad y la coyuntura política de gestión de los programas norteamericanos que promovían la solidaridad hemisférica. Para esto Cota considera que los polos globales y locales en la esfera cultural interactúan en constante tensiones, contradicciones, hibridaciones y resistencias. En esta línea, el historiador propone pensar América latina como una "periferia deseada" a modo de campo fértil para la divulgación de posicionamientos, practicas e influencias que favorecieron las ideas del arte moderno en el continente. Y expone que la presentación de las obras dentro colección se hacía de acuerdo al país de proveniencia como arte arte mexicano o arte brasilero, hasta 1939 que comienza a implementarse en las referencias la categoría de arte latinoamericano. Esto genero una lectura de unidad sobre un inventario de artistas como Jose Orozco, Diego Rivera, David Siqueiros y Cândido Portinari en materialidades como pinturas, gravados y litografias.

En el segundo capítulo, Cota examina en el catalogo de la colección del MoMA la historicidad del arte del continente americano propuesto por el escritor norteamericano Lincoln Kirstein. El historiador plantea que la principal estrategia conceptual en el texto de Kirstein fue la presentación de semejanzas entre América Latina y América del Norte como un tesoro cultural desde la colonización hasta el siglo XX para poner en valor la necesidad de visibilizarse en una esfera global; y en este mismo espectro Cota marca en Kirstein el establecimiento de diferencias en la innovación artística, que a su juicio corresponden a operaciones de dominación por una posición legitima del arte norteamericano en el continente. En este sentido, el autor propone que desde Norteamérica se pautaron las experiencias merecedoras de reconocimiento del termino arte latinoamericano para construir un discurso identitario en el campo artístico. Este presenta un análisis detallado de como se agruparon los países latinoamericanos bajo la denominación de: centro (cuba y México), costa este (argentina, Brasil y Uruguay) y costa oeste (chile, Colombia, Perú, Bolivia). Cota encuentra según el número de adquisiciones que los dos primeros bloques estaban mucho mejor posicionados a diferencia de la costa oeste que tenía una aparición incipiente; esto también explicando los silencios y ausencias de representatividades en la colección. La referencia al arte latinoamericano se convierte en un punto de encuentro de los aspectos geográficos, políticos y culturales.

En el tercer capítulo, Cota teniendo presente publicaciones del historiador del arte y director del MoMA Alfred Barr trabaja cuáles fueron las principales cuestiones que llevaron a la circulación de la colección latinoamericana. Por un lado, el autor del libro destaca que los discursos sobre el arte moderno defendidos por Barr en contra a la producción artística de países totalitarios fueron acogidos por los miembros de las elites economicas, representantes de insituciones artisticas e intelectuales. Por otro lado, Cota expone que las formas de adquisición de la colección por donación y compras se pueden pensar en dos 
fases: la primera entre 1935- 1941 en la que fue resaltado la adquisición los muralistas mexicanos, el grupo de los tres grandes entre los que se encuentran Diego Rivera, José Clemente Orozco y David Alfaro Siqueiros; y otra segunda, en 1942 donde la colección tomo dos premisas la cantidad y la diversidad que demuestra la ampliación de lo latinoamericano.

Cota toma como fuentes primarias para su trabajo las exposiciones y los catálogos de la colección latinoamericana para identificar los cambios conceptuales dentro de la formación de la colección. En estos estudia la convivencia de imágenes y textos en contraste con publicaciones y comunicados provenientes de medios de divulgación, instituciones artísticas y administradores culturales. El historiador contrasta las características de la colección no solo desde su medio interno (el museo), sino que pone en dialogo con un medio externo (administración política y cultural). La dimensión política estudiada por el autor no solo es política cultural, sino que retoma la política de adquisiciones -una política en el arte olvidada desde la perspectiva histórica- con una aproximación cualitativa que recupera el entramado de conexiones internacionales de los representantes del Museo al negociar las obras. En este sentido, el libro de Cota es un aporte directo a la historicidad del arte en la geopolítica para los investigadores interesados en desarrollar trabajos de historia del arte latinoamericano e historia cultural entre 1930 y 1940.

Albertina Cavadía Torres

Estudiante del Doctorado en Historia, Universidad Nacional de San Martín, Argentina; Candidata a Magister en Historia Contemporánea Universidad Nacional de Sarmiento, Argentina; Especialista en Museos, transmisión cultural y manejo de colecciones Universidad de Buenos Aires, Argentina; Historiadora de la Universidad de Cartagena, Colombia 